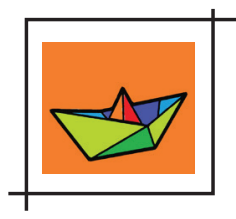

\title{
O PAPEL DAS MÍDIAS NO ESTIGMA SOCIAL DO MORADOR DE FAVELA: REFLEXÕES A PARTIR DO BAIRRO CIDADE NOVA EM FOZ DO IGUAÇU - PR
}

\author{
Viviane da Silva Welter* \\ Tatiane Lima de Paiva** \\ Fátima Regina Cividini*** \\ Denise Rosana da Silva Moraes****
}

Resumo: A modernidade e a globalização reconfiguram relações sociais, econômicas e culturais em um movimento fluido e constante, que parece não ter limites espaciais ou temporais. As novas tecnologias invadiram nossas vidas e hoje temos acesso a informações e notícias oriundas de diversos meios de comunicação, inclusive na palma das nossas mãos. Entretanto, mesmo com o acesso a essas tecnologias, problemas como migrações livres ou forçadas que resultam em crescimento urbano não planejado, segregação socioespacial, desemprego, violência etc. fazem parte dos cenários urbanos. Pessoas vivenciam situações degradantes em seu cotidiano que Ihes tiram a dignidade, e ademais disso, sofrem estigmas por sua condição social. Esse é caso dos moradores do bairro Cidade Nova em Foz do Iguaçu - PR, rotulado como violento. Analisando esse contexto, propusemo-nos neste artigo a refletir sobre a contribuição das mídias na estigmatização do morador de favela, a partir do olhar do bairro Cidade Nova. Para isso, pautamos este estudo em pesquisa bibliográfica, análise de narrativas extraídas de Tatiane Paiva (2018) e de um portal de notícias do bairro estudado, uma entrevista de uma rede de televisão paranaense, além da análise de um rap escrito por um morador do Cidade Nova. Corrobora a tese de que existem diversas estratégias para a construção do estigma, muitas delas legitimadas pelas mídias, mas conclui-se que a partir da organização comunitária, o estigma pode ser desconstruído e negado pela via cultural. Esperamos que este estudo colabore para compreender como o estigma pode ser prejudicial para individuos estigmatizados, que esse é construído no seio da sociedade e, portanto, é passivel de ser superado.

Palavras-chave: Estigma. Mídia. Segregação socioespacial. Favela. Fronteiras.

\footnotetext{
* Doutoranda no Programa de Pós-Graduação Strictu Sensu Sociedade, Cultura e Fronteiras da Universidade Estadual do Oeste do Paraná (Unioeste). E-mail: vivianewelterunioeste@gmail.com

** Doutoranda no Programa de Pós-Graduação Strictu Sensu Sociedade, Cultura e Fronteiras da Universidade Estadual do Oeste do Paraná (Unioeste). E-mail: tatyplug@hotmail.com

*** Doutoranda no Programa de Pós-Graduação Strictu Sensu Sociedade, Cultura e Fronteiras da Universidade Estadual do Oeste do Paraná (Unioeste). E-mail: cividinifatima@hotmail.com

**** Doutora em Educação pela Universidade Estadual de Maringá, professora adjunta e coordenadora do Programa de Pós-Graduação Strictu Sensu Sociedade, Cultura e Fronteiras da Universidade Estadual do Oeste do Paraná (Unioeste). E-mail: denisepedagoga@gmail.com
} 


\section{INTRODUÇÃO}

Quando foi construir a Avenida Beira Rio, tinha a favela do Monsenhor Guilherme [...], ela tinha o lado A e o lado B, o grupo que mandava no B não interferia no A e vice-versa [...], eu vejo que aquilo foi uma limpeza que eles quiseram fazer na cidade, sabe? [...], construir um bairro pra essas pessoas [...], no papel ele é o melhor bairro que existiria em Foz do Iguaçu, só que até hoje tá lutando pra ter posto de saúde [...] então daí pegou todo mundo que era dos lados rivais, que eram concorrentes, na venda de droga de lá das favelas beirando o rio e jogaram aqui [...] sem contar que eles eram rivais, né?! Aqui final de semana no começo era dez mortes, onze mortes, eles entravam em conflito, se matavam tudo, então... [...] agora a gente tá vivendo uma coisa diferente [...]. Agora tem o Almada que é recente, o Nova Andradina que é recente, o Grande Lago [...]. Uns que estão vindo do Bubas [...], eles falam: eu sou do Cidade Nova II, eu sou do Cidade Nova I, ah esse ai é do Andradina, esse vem lá do Almada, [...] o Cidade Nova I, veio primeiro, depois veio o dois, mas a II mora gente que tem mais poder aquisitivo, sabe uma guerra? Dai ali tem a Vila Solidária, que só tem pobre, como se alguém fosse rico aqui, né, mas tudo bem, até nós professor tudo ferrado [...]. Uma divisão imaginária, que gera um monte de conflito (PAIVA, 2018, p. 60)'1.

A narrativa evidenciada se refere à década de 1990, periodo em que o Brasil, assim, como diversos outros países, estava reorganizando sua agenda internacional após o fim da Guerra Fria e passou a aceitar diversas recomendações do Fundo Monetário Internacional (FMI), entre elas, a abertura econômica e desregulamentações com o objetivo de maior crescimento econômico (PECEQUILO, 2008).

Nesse cenário, diversas cidades brasileiras receberam massivos investimentos internos e externos. Em Foz do Iguaçu, os investimentos se deram na melhoria da infraestrutura urbana, principalmente construção de ruas e avenidas, além do planejamento para a resolução do grande déficit habitacional municipal ${ }^{2}$, tendo sido criada para isso, no início da década de 1990, a Companhia de Habitação de Foz do Iguaçu (Cohafoz).

Assim que assumiu a administração municipal de Foz do Iguaçu em 1997, o prefeito Harry Daijó promoveu uma reorganização na Cohafoz, estabeleceu adequações técnicas e administrativas, dando prioridade ao atendimento às populações mais necessitadas, iniciando a remoção de favelas localizadas próximo ao centro da cidade, ao longo do rio Paraná.

Sob a justificativa do desenvolvimento municipal, com base na construção de uma "cidade vocacionada para o turismo" (SOUZA, 2009), ocorreu "a maior remoção da história do município de Foz do Iguaçu" (RIBEIRO, 2015, p. 201), em que moradores das favelas Monse- 
nhor Guilherme, Marinha, Cemitério e Bambu foram removidos para um bairro novo, ainda em construção, chamado Cidade Nova, que não contava com nenhuma infraestrutura pública básica: escolas, postos de saúde, pavimentação, transporte público etc.

Outro agravante evidenciado por Ribeiro (2015) foi a realocação de grupos rivais outrora longe fisicamente, próximos um do outro no novo bairro, o que ocasionou conflitos, resultando em altas taxas de homicídios. Ao contestar o ex-prefeito Harry Daijó em entrevista realizada pelo autor, este afirmou que sabia dos conflitos anteriormente existentes "A gente sabia do conflito, mas tinha certeza de que num lugar melhor tudo ia melhorar" (RIBEIRO, 2015, p. 214).

A migração de um local para o outro, seja dentro da mesma cidade ou entre estados ou países, acompanha a história. No mundo globalizado, a essência das migrações é econômica, como a procura por trabalho em lugares com melhores condições de vida.

Diferente da migração com motivação econômica, inferimos que a mudança para o bairro Cidade Nova se caracterizou por uma remoção e segregação socioespacial, que, por sua vez, ocasionou disputas de territórios e confrontos, principalmente no início do bairro.

A violência ressaltada por Ribeiro (2015) e confirmada neste mesmo estudo pelo ex-prefeito Harry Daijó contribuiu para que os moradores do bairro Cidade Nova sofressem estigmatização.

Grande parte dos moradores do Cidade Nova eram provenientes de processos de desfavelamento, ou seja, já haviam sofrido o estigma por terem sido moradores de favelas ou ocupações. Ao se mudarem para o novo bairro, o estigma os acompanhou, agora devido à violência, além de outros conflitos variados, encontrados corriqueiramente, com a convivência social de diferentes modos de vida, hibridizando-se ou criando fronteiras invisiveis.

0 estigma de bairro marginalizado e violento, provavelmente construido a partir das altas taxas de homicídio no processo de formação inicial do Cidade Nova, foi legitimado pela imprensa, que, por sua vez, contribuiu para que os próprios moradores se enxergassem dessa maneira, "um bairro que, no início, era marginalizado, não só pela imprensa, mas também pelos próprios moradores" (CIDADE NOVA INFORMA, 2014).

Nesse sentido, quando apenas os conflitos ou os pontos positivos de um local são narrados pela mídia, essa coopera para desestimular/estimular a criação de preconceitos, estigmas ou símbolos de prestígio sobre determinados espaços urbanos e pessoas. Essa seleção ou exposição de apenas um fragmento da realidade sobre um fato faz parte de um enquadramento da notícia, sendo um dos padrões de manipulação da grande imprensa (ABRAMO, 2016) e possui importantes reflexos na opinião sobre determinada comunidade, pois a mídia tem um grande poder - integra o cotidiano das pessoas e a informação transmitida forma e reforma opiniões e conceitos dos espectadores.

Adelmo Genro Filho (1987) descreve que as notícias veiculadas na mídia, inicialmente, devem ter o princípio da imparcialidade, ou seja, não devem emitir juízos de valor explícitos, 
mas isso está implícito na própria forma de se apresentar a notícia, na hierarquização e seleção dos fatos a serem noticiados, bem como na linguagem e na repercussão dos fenômenos noticiados e difundidos.

Vale ressaltar que, ao longo do tempo, o bairro Cidade Nova foi se modificando, pessoas morreram, foram embora, outras chegaram e continuam chegando. Após alguns marcos importantes, a comunidade passou a ser conhecida não somente pela violência, mas também pelo diálogo, entre si, com as autoridades locais, com outros bairros, cidades e paises, e isso somente foi possivel a partir de demandas orientadas pela própria comunidade do bairro.

Assim, o objetivo geral deste artigo é refletir acerca do papel das mídias no estigma social do morador de favela, por meio de pesquisa bibliográfica e narrativas de moradores locais (membros do Cidade Nova Informa [CNI]) e uma professora participante do "Projeto Memória", funcionária do Colégio Estadual Ipê Roxo, situado no bairro.

Analisamos, também, a música "Fala favela", do artista Mano Zeu (2011), morador do bairro Cidade Nova, juntamente com conceitos teóricos sobre este estilo musical para compreender de que maneira o rap apresenta/representa os moradores da favela e, principalmente, como as mídias podem reforçar ou desconstruir o estigma negativo de moradores de favela.

Para atingir esses objetivos, organizamos este artigo do seguinte modo: na primeira seção abordamos temáticas que envolvem aspectos resultantes da atualidade, uma vez que a globalização contribui para o deslocamento não só de pessoas, mas de informações (mídia), que por sua vez ressignifica pessoas e espaços, como nos organizamos e como vemos o mundo; na segunda seção, abordamos de forma breve o histórico das mídias e o papel dessas na construção e perpetuação do estigma, além de uma subseção em que analisamos fragmentos de um rap e seu poder para a negação do estigma. Nas considerações finais, fazemos alguns apontamentos sobre a construção e a desconstrução do estigma.

\section{SOCIEDADE, MODERNIDADE E MÍDIA}

Temas como migração e globalização são debatidos a partir de distintas perspectivas e, ao mesmo tempo que ocorrem de forma situada, estão relacionados a fatos que ocorrem no mundo todo. Como Stuart Hall $(2006$, p. 17) afirma, a sociedade está sendo desviada do centro ou movida por forças fora de si mesma, constantemente. Para o autor, as sociedades da modernidade tardia têm por característica a diferença, e tais sociedades se constituem em transversalidades com distintas divisões e incompatibilidades sociais, as quais produzem várias posições de sujeito.

As reflexões de Hall (2006) sobre os estudos de McGrew (1992) e Giddens (1990) compreendem que o mundo pós-moderno contém uma linha comum, nas ênfases no que não é 
contínuo, no que se fragmenta, no que se rompe e no que se desloca. Tais fenômenos devem ser levados em consideração ao discutirmos os efeitos da mudança contemporânea, chamada também de globalização - um processo que transcende fronteiras e conecta as comunidades em novos arranjos de espaço-tempo, tornando-as mais conectadas. A globalização afasta a ideia clássica de sociedade e a transforma em um pensamento de uma vida social ordenada ao longo do tempo e do espaço, conforme afirma Hall (2006).

Ao pensarmos em atravessamento de fronteiras, integrações e conexões, concordamos com Zygmunt Bauman (2005, p. 11), quando defende que a globalização caracteriza o momento histórico atual, o qual ele chama de "modernidade líquida". 0 autor afirma que ela não é como um jogo de quebra-cabeça, que pode ser resolvido baseando-se em um padrão preestabelecido, mas, sim, ser observada como um processo, do mesmo modo como é compreendida e analisada.

A velocidade com que a informação chega até as pessoas é cada vez mais rápida. Nada escapa às câmeras embutidas nos mais distintos aparelhos eletrônicos e tudo isso se torna mídia. Conforme aponta Genro Filho (1987), a mídia estabelece a participação das pessoas no mundo mediado pela "via de sua feição dinâmica e singular", ou seja, a mídia traz a sensação de pertencimento, do qual o individuo consegue reviver aquele recorte histórico noticiado sem a necessidade de se fazer presente nele.

A midia permeia todas as questões atuais, inclusive as que são apontadas por Bauman (2005), quando esse nos alerta para o fato de a globalização não ocorrer de um modo igual para todos. 0 autor explica que mesmo assim ela tem influência sobre as sociedades, as culturas, as identidades, enfim, sobre a vida de todos que habitam este planeta, seja de modo direto ou indireto.

Nesse sentido, Hall (2006) analisa as sociedades de periferia como mais receptivas às influências e ideias vindas de outros lugares, apropriando-se desses conhecimentos e criando novas formas de pensamento.

Luiz Paulo da Moita Lopes (2006, p. 93), ao sintetizar as ideias de Martin-Barbero (2003), Sarlo (2000), Gitlin (2003), Chouliariaki e Fairclough (1999), Milton Santos (2000) e John Thompson (1998), comenta que a mídia ocupa um papel estratégico e importante na nossa sociedade, e que, como espectadores, acreditamos ser parte dela.

Com o avanço do papel da mídia no dia a dia das pessoas, podemos ter uma falsa sensação de que ela pode ser solução de todos os problemas cotidianos ou trazer respostas aos questionamentos pessoais, espirituais, psicossociais.

Segundo Moita Lopes (2006), a mídia torna nossa sociedade semiotizada, ou seja, faz que imagens e sons controlem a vida de quem a consome, construindo identidades e trazendo experiências que ultrapassam o tempo e o espaço real em que vivemos.

A mídia possui essa relevância e notoriedade nas sociedades, porque a comunicação é uma necessidade do ser humano. 0 homem continuamente cria e recria meios para se comu- 
nicar, seja por meio da linguagem escrita, da fala, de sinais ou da arte, e transmite a determinada mensagem desejada.

Além da comunicação, Genro Filho (1987) apresenta a mídia como uma função social, uma forma de satisfazer as necessidades produzidas pela sociedade, de obter informações e de manter-se em dia com os acontecimentos da época, assim como de conhecer o cotidiano e a vida dos grupos sociais e a defesa de ideias e ideologias de um grupo.

A necessidade de comunicação requer o contato entre grupos ou comunidades - pessoas. Por meio dos estudos de Norbert Elias e John Scotson (2000, p. 68), percebemos que o encontro envolve disputas e relações de poder que não acontecem ao acaso, mas são "característicos dos processos a longo prazo e em larga escala a que costumamos referir-nos com termos como 'industrialização', 'urbanização' ou 'desenvolvimento comunitário'".

Nesse sentido, analisamos que o processo de desfavelamento e concomitante remoção e realocação de diversos moradores no bairro Cidade Nova é fruto do "desenvolvimento" e "crescimento econômico" de Foz do Iguaçu, porém sem considerar fatores sociais que contribuíram para a construção do estigma de um bairro estigmatizado.

Para tanto, na próxima seção abordaremos brevemente o histórico da mídia, o poder de manipulação da grande imprensa, a construção e perpetuação do estigma e o papel da mídia nesse processo, além da expressão musical como uma alternativa para a negação do estigma.

\section{A CONSTRUÇÃO E PERPETUAÇÃO DO ESTIGMA E O PAPEL DAS MÍDIAS}

Historicamente, a mídia, segundo os estudos de Thompson (1998), começou a ser difundida na metade do século XVI, por meio de publicações de notícias e informações, a partir do momento em que os periódicos surgiram, de certa forma, inicialmente sendo confiáveis.

A mídia tem um estreito laço com o desenvolvimento da economia capitalista no fim da Idade Média e início da Europa Moderna, e os primeiros consumidores desses materiais eram, de maneira geral, as classes mais instruídas (clero, academia, políticos) e os nobres. Dessa forma, a circulação de notícias vindas de outros lugares ajudou as pessoas a criarem uma percepção de mundo com potencial relevância em suas vidas (THOMPSON, 1998).

A mídia em larga escala para interesses comerciais começou a partir do início do século XIX e, com a globalização, os processos de comunicação e informação foram ficando cada vez mais complexos (THOMPSON, 1998).

Essa complexidade pode ser verificada no poder de influência da mídia, capaz de modelar o psicológico dos indivíduos de maneira que, segundo Santiago Castro-Gomes (2005), para qualquer manifestação do indivíduo para construir seu próprio eu, o sistema capitalista oferta serviços para garanti-lo. 
0 mercado tornou-se especializado e personaliza seus bens às necessidades - fabricadas, artificiais - dos individuos, mantendo-os, assim, sob controle, e esse processo é legitimado com o auxilio da mídia, conforme sustenta Abramo (2016, p. 14):

\begin{abstract}
Dada sua relevância nos mecanismos de socialização, de formação das sensibilidades e dos padrões de apreensão da realidade, a mídia se tornou um instrumento crítico para coordenar ações políticas. Ela descreve, contextualiza, dá sentido, mas também julga, orienta o julgamento e a execução dos atos.
\end{abstract}

Esse poder sedutor também é encontrado nas reflexões de Mariângela Momo e Marisa Costa (2010), em que a sociedade transforma o consumo em uma necessidade, de forma que "o ter" atua como um passaporte para ser incluído em determinados grupos, criando uma cultura na qual se valoriza o ser humano pelo que ele possui. Assim, aqueles que possuem ou aparentam possuir determinados itens tecnológicos ou da moda do momento se tornam estabelecidos e aceitos pelo grupo, enquanto os que não possuem são marcados - estigmatizados.

Ervin Goffman (1988), relevante pesquisador sobre o tema "estigma", salienta a mudança da concepção desse termo ao longo do tempo, ora com conotação positiva, ora negativa. Entretanto, o único momento da história citado pelo autor em que o estigma era considerado positivo foi na era cristã (a partir do século I d.C.), pois representava um sinal de graça divina.

Quando foi criado pelos gregos, bem como na contemporaneidade, a essência do estigma caracterizou-se e caracteriza-se como negativa. 0 que difere nesses dois momentos é que, para os gregos, o estigma se referia a sinais corporais utilizados para marcar algo incomum ou mau sobre o status moral de uma pessoa, e por esse motivo, tal indivíduo deveria ser evitado pelos demais.

Na contemporaneidade, o estigma não precisa estar relacionado apenas a uma evidência corporal, pois o individuo estigmatizado tem sua identidade associada àquilo que é mau, desprezível ou inaceitável por um determinado grupo ou sociedade, apenas por não apresentar as características aceitas por esse grupo. Essa constatação é relevante, uma vez que demonstra que a aversão, o ódio e o desprezo não se desenvolvem apenas em grupos fisicamente distinguiveis, com características físicas que marcam quem deve ser repelido ou evitado em uma sociedade. Atualmente, a construção em torno da marcação dos sujeitos desviantes - os outsiders - atua em elementos mais subjetivos.

Elias e Scotson (2000), ao estudarem três bairros ingleses, verificaram que entre os grupos havia os que se consideravam distintos e, portanto, "melhores" do que outro grupo, considerado por esses inferiores. A principal fonte de distinção entre os grupos não se dava pela cor da pele, classe social, partidarismo político ou nacionalidade, mas, sim, por quanto tempo os grupos estabelecidos moravam na cidade, que se reafirmou como um simbolo de prestígio. Assim, havia uma censura aos membros dos grupos recém-chegados. 
De acordo com Elias e Scotson (2000), os recém-chegados eram privados dos contatos sociais com os residentes mais antigos, os quais se resumiam apenas ao trabalho e ao comércio, pois qualquer contato fora desses espaços teria consequências negativas para a imagem dos estabelecidos.

Em grande parte, essa estratégia obteve êxito porque os outsiders, ao contrário dos estabelecidos, não possuíam coesão, pois eram recém-chegados de lugares distintos tanto da própria Inglaterra quanto de outros paises, o que intensificava sua condição de estrangeiros, pois não eram apenas estranhos aos grupos estabelecidos, como também entre si.

Elias e Scotson (2000) ressaltam que o grupo mais antigo se sentia ameaçado pelos moradores recém-chegados e, além de impedir que os outsiders adentrassem seu círculo, promoviam diversas atividades em associações, bandas, encontros na igreja, entre outros, com o objetivo de reafirmar a coesão de seu grupo estabelecido, seguido da estigmatização dos considerados de fora. 0 objetivo dessas ações era a preservação da identidade do grupo estabelecido e a reafirmação de sua superioridade, ao manter os outros em seu lugar, por não compartilharem do mesmo estilo de vida e conjunto de normas do grupo já estabelecido.

Importante frisar que as características do grupo estabelecido precisavam ser reafirmadas, tanto para si quanto para os outros, produzindo juizos de valor, ao afirmar que seu grupo era bom e o outro era ruim, ou seja, a construção de estereótipos e estigmas para inferiorizar o grupo que os ameaçava. Com a popularização da mídia na Modernidade, essa reafirmação do estigma ocorre com programas ou telejornais, que frequentemente noticiam a violência localizada em determinados bairros ou regiões de uma cidade.

Segundo Goffman (1988), a sociedade cria métodos para categorizar as pessoas, assim como cria conjuntos de características consideradas comuns e naturais para os integrantes de cada uma dessas categorias. Aqueles que são considerados desviantes precisam ser evitados, iniciando-se, assim, o processo de estigmatização.

Esses jogos sociais de classificação são construídos dentro dos próprios grupos, permeados por relações de poder, pois "um grupo só pode estigmatizar outro com eficácia quando está bem instalado em posições de poder das quais o grupo estigmatizado é excluído" (ELIAS; SCOTSON, 2000, p. 23).

Um grupo mais coeso, portanto, hegemônico, estabelece quais práticas, condutas, leis, manifestações culturais etc. devem ser aceitas e quais devem ser evitadas. No entanto, essa classificação é seletiva: "observe-se, também, que nem todos os atributos indesejáveis estão em questão, mas somente os que são incongruentes com o estereótipo que criamos para um determinado tipo de indivíduo" (GOFFMAN, 1988, p. 6).

Além dessa seletividade, vale ressaltar, conforme ressaltam Elias e Scotson (2000), que a estigmatização social não é simplesmente o preconceito individual, mas grupal, em que um grupo utiliza seu posicionamento de poder para estigmatizar e, consequentemente, excluir outro grupo. Isso foi observado pelo exemplo exposto pelos autores, em que os estabelecidos, 
para preservarem suas tradições comunitárias, distintas dos moradores recém-chegados, classificavam os outsiders como baderneiros, sujos, indignos de confiança, indisciplinados etc.

Os estudos clássicos de Elias e Scotson (2000) ilustram de forma incisiva e auxiliam na compreensão do estigma, subsidiada por uma rede de fofocas utilizada para ressaltar convenientemente apenas os feitos considerados simbolos de orgulho que ocorriam nos bairros dos estabelecidos e reafirmar os eventos negativos ocorridos no bairro dos outsiders, mesmo que em nenhum dos grupos imperasse a homogeneidade.

A comparação de um bairro com o outro torna-se próxima da realidade de diversas comunidades, bairros ou cidades, mas, avançando nessa discussão, a mídia teria um papel relevante na afirmação e reafirmação de estigmas na contemporaneidade?

Quanto a esse ponto, recorremos novamente à Thompson (1998, p. 24), que identifica a mídia como um poder simbólico, nascido "[...] na atividade de produção, transmissão e recepção do significado de formas simbólicas", o que convenciona afirmar que ela tem a mesma importância das outras formas de poder existentes na sociedade. Essas ações simbólicas têm capacidade de influenciar as ações dos outros, "[...] provocar reações, liderar respostas de determinado teor, sugerir caminhos e decisões, induzir a crer e a descrer, apoiar os negócios do estado ou sublevar as massas em revolta coletiva".

Segundo Douglas Kellner (2001, p. 123), os produtos midiáticos "não são entretenimento inocente, mas têm cunho perfeitamente ideológico" e incorporam em seus textos várias "estratégias narrativas, construções de imagens e efeitos (por exemplo, cinematográficos, televisivos, musicais) que raramente se integram em uma posição ideológica pura e inocente".

A midia possui papel preponderante na construção do mundo social, pois, com a propagação e maior acesso dos meios de comunicação, novas formas de interação, tipos de visibilidade e redes de difusão de informação foram criados, que podem, muitas vezes, criar informações manipuladas para legitimar interesses (THOMPSON, 1998, p. 109).

Abramo (2016) salienta que podem ser observados ao menos quatro padrões de manipulação das midias, especificamente no telejornalismo: 1) padrão de ocultação, que diz respeito a um "deliberado silêncio militante sobre determinados fatos da realidade" (ABRAMO, 2016, p. 40), ou seja, fatos relevantes são ocultados do público de forma planejada; 2) padrão de fragmentação, em que um fato real completo é dividido e a imprensa seleciona quais partes serão apresentadas ao público, sob pena de perder não apenas o contexto, mas distorcer e criar outra realidade, distante do significado do fato real ocorrido; 3) padrão de inversão: ocorre de diversas formas, apresentando o que é secundário, como a construção textual ou opiniões como o principal, em vez de apresentar o fato em si; e 4) padrão da indução, em que a população é induzida a consumir uma realidade artificialmente inventada.

Esses padrões de manipulação evidenciam que o campo das interações mediadas está minado de relações de poder que mudam rapidamente, de maneiras imprevisiveis e que afetam os espectadores, que podem dar sentidos variados às programações acessadas, pois 
"o sentido que os indivíduos dão aos produtos da mídia varia de acordo com a formação e as condições sociais de cada um" (THOMPSON, 1998, p. 66).

Algumas pessoas ou grupos podem ser mais suscetiveis à receptividade de mensagens que carregam estereótipos e estigmas, sendo influenciados a interpretar tais informações como verdadeiras sobre determinado grupo de pessoas, bairro, cidade, pais etc.

De outro lado, o que é pouco discutido são as consequências da construção do estigma, no que concerne ao processo de inferiorização que fere profundamente os sujeitos estigmatizados, pois os estereótipos, preconceitos e termos pejorativos marcam diferenças, negam identidades, apagam ou encobrem a história, a língua ou produções culturais de um grupo, em um processo estratégico para a manutenção dos padrões ditados por grupos hegemônicos estabelecidos.

Ao analisarmos apontamentos mais específicos sobre o processo da construção do estigma apresentado por Goffman (1988), vemos que a complexidade é ainda mais intensa, pois o indivíduo estigmatizado e inferiorizado deixa de ser considerado uma "criatura comum e total, reduzindo-o a uma pessoa estragada e diminuida" (GOFFMAN, 1988, p. 6 ). 0 autor complementa sobre a relação entre o sujeito "normal" em relação ao sujeito "desviante":

\begin{abstract}
Por definição, é claro, acreditamos que alguém com um estigma não seja completamente humano. Com base nisso, fazemos vários tipos de discriminações, através das quais efetivamente, e muitas vezes sem pensar, reduzimos suas chances de vida: Construímos uma teoria do estigma; uma ideologia para explicar a sua inferioridade e dar conta do perigo que ela representa, racionalizando algumas vezes uma animosidade baseada em outras diferenças, tais como as de classe social (GOFFMAN, 1988, p. 8).
\end{abstract}

A reafirmação constante de estigmas e estereótipos reflete na maneira como os indivíduos estigmatizados se veem e, assim, passam a acreditar nessa identidade construída estereotipada. Segundo Goffman (1988, p. 10), "tornam-no intimamente suscetivel ao que os outros veem como seu defeito, levando-o inevitavelmente, mesmo que em alguns poucos momentos, a concordar que, na verdade, ele ficou abaixo do que realmente deveria ser".

Encontramos correspondência desse fato no caso dos grupos da cidade inglesa, em que a hierarquização e a classificação dos estabelecidos aos outsiders contribuíram para que os membros do grupo estigmatizado considerassem-se humanamente inferiores por não possuírem as virtudes valorizadas pelo grupo estabelecido, pois "quando o diferencial ou poder é muito grande, os grupos na posição de outsiders avaliam-se pela bitola dos opressores, [...] eles se consideram deficientes, se veem como tendo menos valor" (ELIAS; SCOTSON, 2000, p. 28).

Além de os indivíduos ou grupos estigmatizados se considerarem inferiores, eles tendem a orientar seus comportamentos de acordo com essa identidade deteriorada: "dê-se a um grupo uma reputação ruim e é provável que ele corresponda a essa expectativa" (ELIAS; 
SCOTSON, 2000, p. 30). Os autores afirmam que os outsiders, ao se reconhecerem como ruins e sujos, passaram a demonstrar mau comportamento e sentem prazer em fazer exatamente as coisas que Ihes eram censuradas, como um ato de vingança contra os estabelecidos.

Goffman (1988) pontua que o individuo estigmatizado pode também se esforçar sobremaneira para dominar conhecimentos técnicos ou práticas geralmente não desenvolvidas por pessoas de seu grupo estigmatizado como uma tentativa para romper com o estigma.

Nesse sentido, o autor cita Barker (1948), que contribui sobre a insegurança de indivíduos estigmatizados em suas interações sociais ou laborais.

Para a pessoa inabilitada, a incerteza quanto ao status, somada à insegurança em relação ao emprego, prevalece sobre uma ampla gama de interações sociais. 0 cego, o doente, o surdo, o aleijado nunca podem estar seguros sobre qual será a atitude de um novo conhecido, se ele será receptivo ou não, até que se estabeleça o contato. É exatamente essa a posição do adolescente, do negro de pele clara, do imigrante de segunda geração, da pessoa em situação de mobilidade social e da mulher que entrou numa ocupação predominantemente masculina (BARKER, 1948 apud GOFFMAN, 1988, p. 15).

Mesmo inseguros, individuos estigmatizados se esforçam para conquistar seu espaço pari passu aos estabelecidos. Quando alcançam notoriedade, tornam-se exemplos para o local outrora estigmatizado, inclusive noticiados em grandes meios de comunicação, como na manchete: "Menino pobre descobre vocação nos livros que catava no lixo e vira médico"3.

Vale ressaltar que são poucos os casos como esse e que, apesar de aparentar uma benevolência da mídia em noticiar esse mérito, o objetivo principal é a construção do discurso meritocrático de que todos podem ter sucesso, basta ter esforço.

Se as grandes mídias dão atenção apenas a esses tipos de discursos, uma alternativa é a autonomia midiática de comunidades para se expressarem pelas mais diferentes vias e formas, pois a proliferação midiática, para Lúcia Santaella (2003, p. 27), é provocada pelo surgimento de meios "[...] cujas mensagens tendem para a segmentação e diversificação".

Incluídas nessas formas de transmissão de mensagens, a música torna-se um instrumento de expressão das juventudes, sendo considerada até um idioma para Roseli Fígaro e Maria Aparecida Baccega (1999).

Nesse sentido, na seção a seguir, analisamos a expressão das dificuldades enfrentadas pelos moradores do Cidade Nova por meio da música e como essa arte pode ser uma alternativa para negar diversos estigmas atribuídos ao bairro e a seus moradores.

3 - Disponivel em: http://g1.globo.com/globo-reporter/noticia/2015/09/menino-pobre-descobre-vocacao-nos-livros-que-catavano-lixo-e-vira-medico.html. Acesso em: 30 ago. 2018. 


\section{0 poder da expressão para a negação do estigma}

Na música, segundo Kellner (2001, p. 230), na década de 1980, os negros estadunidenses usavam o rap como uma linguagem musical e uma forma privilegiada de resistência à opressão, o "Rap é uma forma de fazer música onde o ' $R$ ' significa rima e ritmo e o 'P' poesia - e em alguns casos política". 0 estilo musical era um meio de explanar as formas de abuso e violência sofrida pelos negros nas comunidades (guetos), desmascarando-as:

0 rap transmitia as experiências e as condições dos americanos negros que viviam em guetos violentos e, assim, se transformou num poderoso veículo de expressão política, traduzindo a raiva dos negros diante da crescente opressão e diminuição das oportunidades de progresso, quando a simples sobrevivência passou a ser um grave problema (KELLNER, 2001, p. 231).

0 rap atravessou fronteiras e atualmente é um estilo musical encontrado no Brasil com semelhantes expressões de violência e da falta de dignidade humana e de condições de vida das pessoas que vivem em comunidades carentes.

Os rappers - nome dado aos que cantam o rap -, de acordo com Kellner (2001, p. 232), muitas vezes usam pseudônimos, sendo uma referência às máscaras na tradição da cultura africana. No anonimato, ao assumirem outra personalidade, sentem-se em liberdade para expressar suas inquietudes, falando em nome do grupo ou da comunidade em que estão inseridos, ou até por eles mesmos.

Mano Zeu, rapper iguaçuense, na música "Fala favela"4, retrata parte da realidade das favelas brasileiras a partir da sua realidade local, visto que é morador de um dos bairros mais estigmatizados em Foz do lguaçu - o Cidade Nova.

A letra faz um apelo ao esquecimento dos governos à comunidade em que ele vive e pede que a favela não se cale diante da violência e do abuso de poder por parte dos governantes, o que evidencia uma letra musical de resistência.

No início da música, antes de começar a letra propriamente dita, aparecem diálogos com pessoas aleatórias sobre as relações fronteiriças cotidianas, como morar no Brasil e trabalhar no Paraguai, além de falas sobre os locais onde já trabalhara. Ressaltam também a importância de ter voz sobre o que pensa e sente, não repetir os erros, a esperança de mudar de vida e ser aceito na sociedade como um cidadão participativo. Kellner (2001) descreve que no rap aparecem sons desordenados, ruídos de carros de polícia e agitação urbana.

4 - A música foi lançada na plataforma de vídeos YouTube em 9 de fevereiro de 2011 e faz parte do CD Brasil llegal. Disponivel em: https://www.youtube.com/watch?v=HU5Jlkhknug. Acesso em: 13 jul. 2018. 
Percebemos que a resistência, por meio da arte, nesse caso, o rap, se torna uma maneira de as comunidades marginalizadas da sociedade não se calarem, mas de reagir, de participar e empoderar-se diante das adversidades encontradas, buscando assim outros modos de ação, conforme afirma Maria Elza Mendes:

\begin{abstract}
[...] nós sofremos aqui, agora já é bem menos, mas durante um período, você não podia sair daqui para procurar um emprego. Tinha vaga, já estava quase 90\% acertado que era sua, mas se falasse que morava no Cidade Nova pronto, a resposta era "ah, não tem vaga, vamos ver, depois nós te ligamos". E o pessoal do Cidade Nova ficava na marginalidade mesmo, é a margem da margem. [...] Mas mudou muito. Porque, por mais que as políticas públicas não cheguem, a comunidade está fazendo por si. Não estou falando só da Biblioteca Comunitária, estou falando da rede de comércio que aumentou, estou falando da qualidade de vida (CIDADE NOVA INFORMA, 2014).
\end{abstract}

Essa narrativa demonstra o estigma do Cidade Nova, prejudicando seus moradores em processos seletivos de emprego. Por outro lado, ressalta que, mesmo com o descaso do governo, a comunidade do bairro tem se organizado para transformar sua realidade e isso envolve a cultura, como a expressão musical por meio do rap, por exemplo.

0 rap pode ser considerado uma mistura cultural de música, dança e canto, apropriando as experiências e as preocupações com o cotidiano, conforme os trechos da música do Mano Zeu (2011):

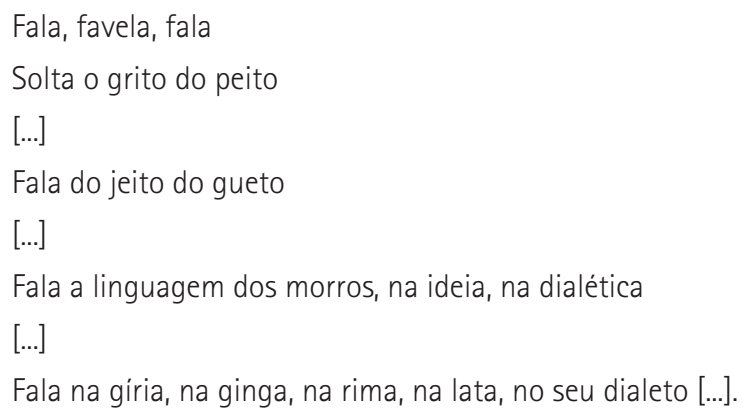

Mano Zeu (2011) mostra elementos afro durante a música nos trechos "na ginga do capoeirista", "ao som do cavaco em meio aos barracos", "ouça nossas vozes contra os algozes ao som do tambor africano" e "que o gueto não aceita mordaça", colocando a música como uma forma de resistência à opressão.

Esses trechos evidenciam o "P" de política, ressaltado por Kellner (2001), ao denunciar a forma como o Estado se apresenta para comunidades como aquela em que o rapper está inserido. Os trechos "fala do desgoverno do estado" e "fala da falta de ética" traduzem a 
incompetência do Estado em garantir condições dignas para que as pessoas possam participar da sociedade.

Além disso, a letra aborda diretamente o estigma de bairro violento ao negá-lo "fala que aqui não é só bala" e que a discriminação não é correta "de quem criminaliza um povo e acha que isso é correto" (MANO ZEU, 2011).

Não apenas as comunidades sofrem com estigmatizações, mas as instalações públicas presentes nos locais, pois seus funcionários também se tornam vítimas da marginalização da sociedade. No colégio público Ipê Roxo, localizado no Cidade Nova, são desenvolvidas atividades por meio dos projetos em parceria com moradores, funcionários da escola e funcionários das universidades próximas da comunidade, e esses vêm ganhando visibilidade das mídias locais nos últimos anos, sendo alvos de reportagens, entrevistas e de estudos acadêmicos, causando, assim, uma inversão de discursos, se comparado com os anos anteriores.

É possivel perceber que antes do "Projeto Memória" e da criação do $\mathrm{CNI}^{5}$, o discurso retratado pela mídia em relação ao bairro era outro. 0 que a mídia evidenciava era a violência, a ilegalidade e outros assuntos de teor negativo, resultando em marginalização, discriminação, preconceito, enfim, práticas que, ao contrário do que ocorre hoje, implicavam uma inferiorização das pessoas que viviam no local.

Conforme afirma a professora Maria Nelda Matias Bassi, colaboradora do "Projeto Memória", em reportagem à Rede Paranaense de Comunicação (RPC) fora valoriza muito mais aquilo que aparece de ruim, então a gente quer mostrar o que tem de bom porque tem muita coisa boa, tem muita gente boa no bairro Cidade Nova, não é só violência".

A cultura da mídia pode ser considerada algo intrinsecamente político. De acordo com Kellner (2001, p. 125), ela fomenta determinadas posições políticas e também funciona como instrumento auxiliar de dominação ou resistência. Thompson (1998, p. 14) afirma que o uso dos meios de comunicação "[...] transforma a organização espacial e temporal da vida social, criando novas formas de ação e interação [...]".

Santaella (2003) apresenta a mídia na era digital como um instrumento de acesso, alastrando o conhecimento e dando voz às ideias e às expressões culturais. Mano Zeu (2011) ressalta em sua letra a importância da era digital para que a voz da comunidade seja ouvida:

\footnotetext{
5 - 0 "Projeto Memória" foi realizado no Colégio Estadual Ipê Roxo entre os anos de 2010 e 2014, construído em conjunto com participantes do "Projeto Observatório" de educação/projeto de pesquisa/extensão: Formação Continuada em Leitura, Escrita e Oralidade.

6 - Matéria veiculada pela RPC em março de 2016, com a chamada: "No Colégio Ipê Roxo, estudantes fizeram trabalho de valorização da história do bairro. Foz do Iguaçu". Disponivel em: http://g1.globo.com/pr/oeste-sudoeste/paranatv-1edicao/videos/t/edicoes/v/no-colegio-iperoxo-estudantes-fizeram-trabalho-de-valorizacao-da-historia-do-bairro/4924279/. Acesso em: 10 set. 2018.
} 
Invade as faculdade, notícias e um mundo não tão distante Fala na web, nos blog, no site, nas televisões, nos jornais $\mathrm{Na}$ voz estridente no megafone dizendo que o povo quer paz Mas a paz com voz, com consciência de classe [...].

As faculdades, de maneira geral, foram historicamente espaços frequentados pelas classes mais abastadas da sociedade. Mano Zeu, ao "invadir" as faculdades com a sua música, demonstra que as classes mais pobres começaram - de forma lenta - a ter acesso à educação superior e que o rap é um estilo musical ouvido pelos universitários.

Ao citar blog, web e site, reconhece que os meios digitais contribuem para a disseminação de sua música. Thompson (1998, p. 13) disserta que "o uso dos meios de comunicação implica a criação de novas formas de ação e de interação no mundo social, novos tipos de relações sociais e novas maneiras de relacionamento do indivíduo com os outros e consigo mesmo". Dessa forma, o rap se torna um meio de expressão e de mostrar as classes mais pobres e seu cotidiano para a sociedade.

Quando Mano Zeu (2011) declara na música que "favela também é cultura", mostra para a sociedade um universo à parte de pessoas que também sentem, pensam e produzem conteúdo expressando seu cotidiano por meio da arte:

No rap, no funk repente,

No samba, no rock, no reggae ou forró

[...]

Fala com o corpo nos passos da dança

Ao som que o DJ põe na pista

[...]

Com fotografia, filme, poesia, com circo e literatura

Nos traços, nas telas, grafite, teatro, o povo se manifestando [...] (MANO ZEU, 2011).

Momo e Costa (2010, p. 979) relatam que as imagens que passam por nós criam significados, "[...] produzem identidades, instauram verdades e constituem sujeitos". E Santaella (2003, p. 30), com análises semelhantes, narra que as tecnologias "[...] moldam nossa sensibilidade e nossa mente, muito especialmente as tecnologias digitais, computacionais, que são tecnologias da inteligência". Mano Zeu, ao colocar sua música para acesso aberto, amplia a visibilidade da comunidade onde vive e traz novos significados a ela.

Para Kathryn Woodward (2000), uma das principais colaborações da política de identidade tem sido a de edificar uma política da diferença, a qual revoluciona a estabilidade das categorias biológicas e a constituição de oposições binárias. Em relação aos novos movimentos sociais, a autora afirma que eles historicizaram a experiência, dando ênfase às dife- 
renças entre grupos marginalizados como modo alternativo à universalidade da opressão. Woodward (2000, p. 50) declara que a diferença pode ser construída de duas formas: negativamente "por meio da exclusão ou da marginalização daquelas pessoas que são definidas como 'outros' ou forasteiros" e, em contrapartida, "ela pode ser celebrada como fonte de diversidade, heterogeneidade e hibridismo, sendo vista como enriquecedora". Em entrevista à revista 100 Fronteiras, Maria Elza Mendes explica como o $\mathrm{CNI}$ age em relação à diferença:

[...] na instituição não temos nenhum tipo de preconceito, é proibido aqui dentro qualquer tipo de preconceito. Nós temos que respeitar cada indivíduo como ele é, posso não concordar com a opinião de alguém, alguém pode não concordar com a minha, mas preciso respeitar. É preciso ficar muito claro que temos grandes talentos em nosso bairro (CIDADE NOVA INFORMA, 2014).

Essa afirmação ressalta a diversidade relatada no rap de Mano Zeu, em que diferentes formas de expressões são valorizadas, demonstrando outros modos de força e resistência por parte dos moradores dessa comunidade. Porém, é importante ressaltar que o fato de haver um trabalho importante na comunidade para a valorização do diferente não garante a ausência de conflitos, até mesmo porque fazemos parte de um mundo moderno e globalizado, uma sociedade fluida e complexa, na qual surgem subjetividades e adotamos identidades híbridas/insurgentes. Logo, pensar em viver em um vácuo de harmonia não corresponderia a este mundo, por mais estabelecida que qualquer comunidade possa ser.

Sobre os processos de identificação, Maria Elena Pires-Santos (2004), parafraseando Deleuze, nos explica que eles nos possibilitam - de várias formas e levando-se em consideração várias regras - a geração de modos de existência, como os que vimos relatando neste artigo. Assim como estilos de vida, de tal modo também nos constituímos como sujeitos amarrados a teias de significados (GEERTZ, 1989), ou seja, dessa somatória, surge a possibilidade de se construir a subjetividade. Pires-Santos $(2004$, p. 80) caracteriza a subjetividade de modo metafórico:

seria o sangue na pulsação que, levando vida a todos os órgãos, nunca é o mesmo, já que a cada instante milhões de células morrem e outros milhões nascem simultaneamente, não sendo portanto nunca o mesmo, ou seja, é necessário que a cada instante aconteça a morte para que prevaleça a vida.

Assim, por meio de novos canais de comunicação podemos desconstruir estigmas por vias culturais, seja por meio da música, conforme analisado neste artigo, mas, igualmente, pela poesia, teatro, dança, pintura etc. Concordamos, então, que a desconstrução do estigma passa por sua negação. 


\section{CONSIDERAÇÕES FINAIS}

O Brasil, para se reorganizar econômica e politicamente no final do século XX, precisou se submeter a recomendações dos paises desenvolvidos para alcançar crescimento e desenvolvimento. Para isso, diversas cidades começaram a receber investimentos externos para adequação de infraestrutura.

Entre essas cidades, estava Foz do Iguaçu, com elevado déficit habitacional em decorrência do recebimento de diversos imigrantes ao longo do século XX. Para resolver esse problema e posicionar o município como destino de turismo, inúmeras famílias fizeram parte de um processo de remoção de antigas favelas para um novo bairro - o Cidade Nova.

Entretanto, não foram levadas em consideração as subjetividades de cada grupo, tendo sido realocados moradores outrora distantes fisicamente em espaços próximos no novo bairro, o que causou conflitos por disputa de venda de drogas, ocasionando um aumento das taxas de homicídios. A partir disso, o bairro em questão passou a ser estigmatizado como violento e marginalizado.

Esse estigma foi replicado e ampliado pela mídia, ao transmitir os acontecimentos violentos ocorridos no bairro, reforçando a ideia de que a comunidade é violenta, dificultando possibilidades de emprego, o que contribui para a perpetuação do estigma, dificultando a tomada de dignidade.

0 contraponto dessa visão está na organização dos moradores do bairro (CNI e Centro Comunitário) e de projetos de universidades voltados ao resgate da história e das dificuldades, que transmitem uma imagem positiva dos moradores, contribuindo, assim, para que se desconstruam os estigmas atribuidos ao bairro e aos moradores.

De forma específica, analisamos a letra do rapper Mano Zeu e narrativas de funcionários do Colégio Ipê Roxo sobre as atividades desenvolvidas no estabelecimento. 0 rap é tradicionalmente uma música de resistência ao sistema opressor e também ao sistema político vigente, o qual exclui as populações à margem da sociedade.

A música "Fala favela" é uma reação ao estigma de que as comunidades não possam ter seus próprios significados, linguagens e cultura, denunciando a violência estrutural que 0 bairro sofre e apresentando parte do cotidiano vivido pelos moradores.

Além disso, aparece nas narrativas uma separação interna daqueles que vivem há mais tempo no bairro e os recém-chegados, e também daqueles que vivem nos novos bairros, criados depois do Cidade Nova, por exemplo, o Cidade Nova II, Andradina, Grande Lago, entre outros.

Essas fronteiras não visiveis promovem conflitos e preconceitos entre os moradores dos bairros, reforçando os argumentos de Elias e Scotson (2006), que trazem os conceitos de "estabelecidos" e "outsiders", de acordo com os quais, aqueles que são recém-chegados (outsiders) são segregados, considerados inferiores àqueles que já estão no local há mais tempo (estabelecidos). 
A perpetuação desses estigmas faz que os outsiders incorporem essa identidade imposta e, com isso, submetam-se a situações e violências, aceitando-as como algo natural, que faz parte de seu cotidiano.

Verificamos, então, que o morador estigmatizado fora de seu bairro, quando menciona onde mora, ao encontrar com novos recém-chegados, inverte a lógica, estigmatizando-os. Isso confirma as ideias de Goffman (1998) de que o que é aceito ou não em determinada comunidade depende do grupo mais coeso, homogêneo e, portanto, com maior poder. Porém, isso pode mudar de um local para outro e ao longo do tempo. 0 que pode ser considerado um fator de estigma ou prestígio hoje pode ser diferente de um grupo para o outro ou se comparado com o passado. Esperamos que este estudo possa contribuir para as reflexões referentes ao poder ultrajante da construção do estigma de moradores de favela e outras minorias, legitimado e perpetuado pela mídia, que interfere na maneira como um grupo estigmatiza outro e como o próprio grupo se vê perante o restante da sociedade. Essa realidade não está dada, foi construída e é passivel de desconstrução, sendo a via cultural um relevante caminho, como o rap do Mano Zeu, que desconstrói o estigma e demonstra que o Cidade Nova "não é só bala", tem cultura, tem diversidade e luta para que suas demandas sejam ouvidas.

\title{
The role of media in the social stigma of the favela resident: reflections from the Cidade Nova neighborhood in Foz do Iguaçu - PR
}

\begin{abstract}
Modernity and globalization have reconfigured social, economic and cultural relations in a fluid and constant movement that seems to have no spatial or temporal limits. New technologies have invaded our lives and today we have access to information and news from various media, including in the palm of our hands. However, even with all access to the technologies, problems such as free or forced migrations that result in unplanned urban growth, socio-spatial segregation, unemployment, violence, etc. are all part of urban settings. People experience degrading situations in their daily lives that deprive them of their dignity, and in addition, suffer stigmas due to their social condition. This is the case of residents of the Cidade Nova neighborhood in Foz do Iguaçu - PR, labeled as violent. Analyzing this context, we propose in this article to reflect on the contribution of the media in the stigmatization of the favela resident, from the perspective of the Cidade Nova neighborhood. For this, we base this study on bibliographic research, analyses of narratives extracted from Paiva (2018) and a news portal of the studied neighborhood, an interview from a Paraná television network, besides the analysis of a rap written by a resident of Cidade Nova. It corroborates the thesis that there are several strategies for the construction of stigma, many of them legitimated by the media, but with community organization the stigma can be deconstructed and denied by the cultural way. We hope this study will help to understand how stigma can be detrimental to stigmatized individuals, that it is built within society and therefore can be overcome.
\end{abstract}

Keywords: Stigma. Media. Socio-spatial segregation. Favela. Boarders. 


\section{REFERÊNCIAS}

ABRAMO, P. Padrões de manipulação na grande imprensa. 2. ed. São Paulo: Fundação Perseu Abramo, 2016.

BAUMAN, Z. Identidade: entrevista a Benedetto Vecchi. Tradução Carlos Alberto Medeiros. Rio de Janeiro: Jorge Zahar, 2005.

CASTRO-GOMEZ, S. Ciências sociais, violência epistêmica e o problema da 'invenção do outro'. In: LANDER, E. (org). A colonialidade do saber: eurocentrismo e ciências sociais: perspectivas latino-americanas. Ciudad Autónoma de Buenos Aires: Clasco, 2005. p. 87-95. (Colección Sur-Sur). Disponivel em: http://biblioteca.clacso.edu.ar/ar/libros/lander/pt/lander.html. Acesso em: 25 abr. 2018.

DOCUMENTÁRIO Panambi. Coordenadora Cristiane Grando. Foz do Iguaçu, Unila, 2017. Disponivel em: http://cidadenovainforma.blogspot.com/2016/01/slides-do-poster-digitalpanambi-da.html. Acesso em: 13 jul. 2018.

ELIAS, N.; SCOTSON, J. Os estabelecidos e os outsiders: sociologia das relações de poder a partir de uma pequena comunidade. Tradução Vera Ribeiro. Rio de Janeiro: Jorge Zahar, 2000.

FíGARO, R.; BACCEGA, M. A. Sujeito, educação e cultura. Comunicação \&t Educação, São Paulo, v. 15, p. 62-80, maio/ago. 1999.

GEERTZ, C. J. A interpretação das culturas. Rio de Janeiro: LTC, 1989.

GENRO FILHO, A. O segredo da pirâmide: para uma teoria marxista do jornalismo. Porto Alegre: Tchê!, 1987.

GOFFMAN, E. Estigma: notas sobre a manipulação da identidade deteriorada. Tradução Márcia Bandeira de Mello Leite Nunes. 4. ed. Rio de Janeiro: LCT, 1988.

HALL, S. Quem precisa da identidade? In: SILVA, T. T. da. (org.). Identidade e diferença: a perspectiva dos estudos culturais. Petrópolis: Vozes, 2000. p. 103-133.

HALL, S. A identidade cultural na pós-modernidade. 11. ed. Rio de Janeiro: DP\&A, 2006.

KELLNER, D. A cultura da mídia: estudos culturais: identidade e política entre o moderno e 0 pós-moderno. Bauru: Edusc, 2001.

KOJUNSKI, M. Cidade Nova na visão de Maria Elza Mendes - 2013. Papo Sério com Maria Elza Mendes. Foz do Iguaçu, março de 2014. Disponivel em: http://cidadenovainforma.blogspot. com/2014/03/papo-serio-com-maria-elza-mendes.html. Acesso em: $1^{\circ}$ set. 2018.

MANO ZEU. Fala Favela. Foz do Iguaçu/PR: Stúdio lô Comunitáriô, 2011. Disponível em: https://www.youtube.com/watch?v=HU5Jlkhknug. Acesso em: 13 jul. 2018. 
MOITA LOPES, L. P. Identidades fragmentadas. Campinas: Mercado de Letras, 2002.

MOITA LOPES, L. P. Linguística aplicada e vida contemporânea: problematização dos construtos que têm orientado a pesquisa. In: MOITA LOPES, L. P. (org.) Por uma linguistica aplicada indisciplinar. São Paulo: Parábola, 2006. p. 13-44.

MOMO, M.; COSTA, M. V. Crianças escolares do século XXI: para se pensar uma infância pós-moderna. Cadernos de Pesquisa, v. 40, n. 141, p. 965-991, set./dez. 2010.

PAIVA, T. L. de P. Ser aluno transfronteiriço em contexto de fronteira: representações de identidades. 2018. Dissertação (Mestrado em Sociedade, Cultura e Fronteiras) - Universidade Estadual do Oeste do Paraná, Foz do Iguaçu, 2018.

PECEQUILO, C. S. A politica externa do Brasil no século XXI: os eixos combinados de cooperação horizontal e vertical. Revista Brasileira de Política Internacional, Brasília, v. 51, n. 2, p. 136-156, dez. 2008. Disponivel em: http://www.scielo.br/scielo.php?script=sci_arttext\&tpid= S0034-73292008000200009\&t|ng=enEtnrm=iso. Acesso em: $1^{\circ}$ set. 2018.

PIRES-SANTOS, M. E. O cenário multilíngue/multidialetal/multicultural de fronteira e o processo identitário "brasiguaio" na escola e no entorno social. 2004. Tese (Doutorado em Linguística Aplicada) - Instituto de Estudos da Linguagem, Unicamp, Campinas, 2004.

PORTAL CIDADE NOVA INFORMA. Disponivel em: http://cidadenovainforma.blogspot.com/ 2014/03/papo-serio-com-maria-elza-mendes.html. Acesso em: 10 set. 2018.

RIBEIRO, D. G. Metamorfoses na cidade: tensões e contradições na produção e apropriação do espaço urbano em Foz do Iguaçu. 2015. Dissertação (Mestrado em Ciências Sociais) - Universidade Estadual do Oeste do Paraná, Toledo, 2015.

SANTAELLA, L. Da cultura das mídias à cibercultura: o advento do pós-humano. Revista Famecos, Porto Alegre, n. 22, p. 23-32, dez. 2003.

SOUZA, A. D. de. Formação econômica e social de Foz do Iguaçu: um estudo sobre as memórias constitutivas da cidade (1970-2008). 2009. Tese (Doutorado em História Econômica) Universidade de São Paulo, São Paulo, 2009.

THOMPSON, J. B. A mídia e a modernidade: uma teoria social da mídia. 5. ed. Petrópolis: Vozes, 1998.

WOODWARD, K. Identidade e diferença: uma introdução teórica e conceitual. In: SILVA, T. T. da. Identidade e diferenças: a perspectiva dos estudos culturais. Petrópolis: Vozes, 2000. p. 7-72.

Recebido em novembro de 2020. Aprovado em novembro de 2020. 